\title{
Urinary Excretion of Endogenous Hydroxyproline by Normal Male Infants
}

\author{
M.K. YounoszaI, D.W. Andersen, L.J. FileR, Jr., and S.J. Fomon ${ }^{[21]}$ \\ Department of Pediatrics, State University of Iowa, Iowa City, Iowa, USA
}

\begin{abstract}
Extract
Rates of urinary excretion of total hydroxyproline by 38 normal fullsize male infants were determined on 176 occasions. Each urine collection period was 72 hours. When the period of urine collection was begun between the fourth and eighth day of life, mean rate of excretion was $30.6 \mathrm{mg} /$ day (standard deviation $6.9 \mathrm{mg} /$ day). Maximal rates of urinary excretion were observed between 21 and 60 days of age (mean: $48.1 \mathrm{mg} /$ day; standard deviation $9.7 \mathrm{mg} /$ day). Between 121 and 582 days of age, mean rate of excretion had decreased slightly to $43 \mathrm{mg} /$ day.

Eleven infants were each studied on at least five occasions between 20 and 120 days of age. Mean rate of urinary excretion of hydroxyproline by each infant was shown to be significantly correlated with rate of gain in length but not with rate of change in weight or surface area.
\end{abstract}

\section{Speculation}

During normal infancy it seems probable that a major proportion of the hydroxyproline excreted in the urine is derived from collagen of bone. Rate of excretion probably parallels rate of bone growth. Thus, any disorder that depresses the normal rate of linear growth is likely to result in sharp diminution of urinary excretion of hydroxyproline. Such a biochemical index of growth may be clinically useful.

\section{Introduction}

The nonessential amino acid, hydroxyproline, accounts for about $13 \%$ by weight of collagen and about $1.5 \%$ by weight of elastin [18]. Because hydroxyproline is not found in other body tissues and because the amount of collagen in the body is so much greater than the amount of elastin, urinary excretion of endogenous hydroxyproline is derived almost entirely from collagen. A number of studies have suggested that rate of urinary excretion of hydroxyproline reflects rate of collagen metabolism $[2,6,7,8,9,11,13,15,17,18,19]$. Studies of hydroxyproline excretion may therefore be clinically useful and may contribute to our understanding of growth.

Newly formed collagen is soluble in neutral salt solutions and is metabolically quite active, while mature collagen is insoluble and metabolically relatively inert. Although newly formed collagen accounts for only a small percentage of total body collagen, its contribution to urinary excretion of endogenous hydroxyproline is relatively great. In view of this considerable contribution of newly formed collagen to urinary excretion of hydroxyproline, it is not surprising that rates of excretion, expressed as milligrams/day, have generally been reported to be somewhat greater in children than in adults. 
The present study was undertaken for two reasons: First, to provide additional data on urinary excretion of endogenous hydroxyproline by normal infants; second, to explore the relationship between urinary excretion of endogenous hydroxyproline and rate of increase in length, reflecting rate of bone growth.

\section{Subjects and Feedings}

Thirty-eight normal fullsize male infants were studied. Birth weight ranged from 2.56 to $5.01 \mathrm{~kg}$ with mean of $3.43 \mathrm{~kg}$. Six infants weighed less than $3.0 \mathrm{~kg}$ at birth. Twenty-five infants were studied only once and were between 4 and 10 days of age when the 72-hour collection of urine was begun. These infants were born in the University Hospitals of unwed mothers and were observed while awaiting disposition by a placement agency. The other 13 subjects were children of students in the University or of other individuals living in the community and remained at home except when admitted to the Metabolic Unit for performance of metabolic balance studies. Thirteen infants were studied serially with 6 to 17 collections of urine obtained from each infant. One infant was studied only once (at the age of 190 days) and one was studied only three times (between the ages of 526 and 582 days).

All infants were fed ad libitum with formulas providing $67 \mathrm{kcal} / 100 \mathrm{ml}$. These formulas provided the sole caloric intake until 120 days of age. After 120 days of age, additional collagen-free foods were permitted. Meat, fish, gelatin, jello, ice cream and candy were specifically prohibited. Hydroxyproline excreted in the urine could therefore be considered to be of endogenous origin.

\section{Procedures and Methods}

Rates of growth in length and weight were determined as described previously $[4,5]$. Surface area was estimated from a nomogram.

Urine was collected on metabolic beds in such a manner that fecal contamination of the urine did not occur $[3,5]$. All collections were periods of 72 hours. Specimens were stored in a refrigerator until the end of a collection period and then acidified to approximately $\mathrm{pH} 1.0$ and maintained at room temperature until hydroxyproline determinations were made. Loss of hydroxyproline during the collection period was less than $5 \%$ of the total as judged from comparison of results of determinations on urine collected in jars with and without acid. Duration of storage at room temperature after acidification could not be shown to influence the result of hydroxyproline determination. Because content of hydroxyproline was found to de- crease during storage of unacidified urine even when frozen, determinations of hydroxyproline were made only with specimens that had been acidified immediately after collection.

In determining hydroxyproline content of urine, hydrolysis was carried out as described by Prockop and Udenfriend [14]. The method of Neuman and Logan [12] as modified by Serafini-CESSI and Cessi [16] was then carried out. All values reported refer to total (i.e. free plus peptide-bound) hydroxyproline.

\section{Results}

Results of analysis of 176 samples of urine, each representing a 72-hour period of collection, are presented in table I. Ages of the infants refer to age on the first day of the collection.

\section{Relation to Age, Weight and Surface Area}

As may be seen from figure 1 , rates of urinary excretion of hydroxyproline, expressed as milligrams per day, increased rather rapidly during the early days of life and then, with relatively few exceptions, remained between 20 and $70 \mathrm{mg} /$ day.

Because rates of urinary excretion ( $\mathrm{mg} /$ day) remained rather constant between about 10 and 200 days of age while body length and weight rapidly increased, rates of excretion expressed in relation to body weight $(\mathrm{mg} / \mathrm{kg} /$ day $)$ or surface area $\left(\mathrm{mg} / \mathrm{m}^{2} /\right.$ day $)$ decreased with increasing age (figs. 2 and 3). After 200 days of age, only 17 observations were made and these varied from 2.0 to $7.7 \mathrm{mg} / \mathrm{kg} /$ day and from 44.4 to $162.2 \mathrm{mg} / \mathrm{m}^{2} /$ day.

\section{Relation to Change in Length, Change in Weight and Change} in Surface Area

Serial studies of 11 infants were considered satisfactory for analysis of mean urinary excretion of hydroxyproline in relation to rate of gain in length, weight and surface area. Each of these infants was studied on at least five occasions at intervals of at least two weeks between the ages of 20 and 120 days. Results of these studies are presented in table II and figures 4-6. The mean rate of urinary excretion of hydroxyproline (mg/day) for each infant during the 100-day period is plotted in figure 4 against his mean rate of gain in length $(\mathrm{mm} /$ day), in figure 5 against his mean rate of gain in weight (gm/day) and in figure 6 against his mean rate of increase in surface area. Neither rate of gain in weight nor rate of increase in surface area was significantly correlated with rate of excretion of hydroxyproline. However, the regression of urinary excretion of hydroxyproline $(\mathrm{mg} / \mathrm{day})$ on rate of change in length $(\mathrm{mm} /$ day) demonstrated a coefficient of correlation of 0.74 . 
Table I. Summary of data on urinary excretion of hydroxyproline by normal male infants

\begin{tabular}{|c|c|c|c|c|c|}
\hline $\begin{array}{l}\text { Age }^{1} \\
\text { (days) }\end{array}$ & $\begin{array}{l}\text { Number of } \\
\text { subjects }\end{array}$ & $\begin{array}{l}\text { Number of } \\
\text { studies }\end{array}$ & $\begin{array}{l}\text { Excretion of } \\
\mathrm{mg} / \text { day }\end{array}$ & $\begin{array}{l}\text { oxyproline }{ }^{2} \\
\mathrm{mg} / \mathrm{kg} / \text { day }\end{array}$ & $\mathrm{mg} / \mathrm{m}^{2} /$ day \\
\hline $4-8$ & 27 & 27 & $30.6(6.9)$ & $9.1(1.6)$ & $146.0(26.4)$ \\
\hline $9-20$ & 11 & 15 & $38.8(10.2)$ & $10.7(2.4)$ & $175.1(41.0)$ \\
\hline $21-60$ & 13 & 31 & $48.1(9.7)$ & $10.7(2.4)$ & $191.1(37.4)$ \\
\hline $61-120$ & 13 & 44 & $45.0(8.1)$ & $7.5(1.5)$ & $150.2(27.0)$ \\
\hline $121-200$ & 14 & 42 & $42.9(9.8)$ & $5.8(1.6)$ & $123.7(28.6)$ \\
\hline 201-582 & 5 & 17 & $43.3(16.4)$ & $4.2(1.5)$ & $95.9(33.0)$ \\
\hline
\end{tabular}

1 Indicates age at time the 72-hour collection of urine was begun.

${ }^{2}$ Average daily excretion during three days of observation. Mean values with standard deviations in parentheses.

Table II. Relation of urinary excretion of hydroxyproline to change in length and weight of male infants between 20 and 120 days of age

\begin{tabular}{|c|c|c|c|c|c|c|}
\hline Subject & $\begin{array}{l}\text { Birth weight } \\
\text { (g) }\end{array}$ & $\begin{array}{l}\text { Number } \\
\text { of studies }\end{array}$ & $\begin{array}{l}\text { Change in } \\
\text { length } \\
\text { (mm/day) }\end{array}$ & $\begin{array}{l}\text { Change in } \\
\text { weight } \\
\text { (g/day) }\end{array}$ & $\begin{array}{l}\text { Change in } \\
\text { surface area } \\
\left(\mathrm{cm}^{2} / \text { day }\right)\end{array}$ & $\begin{array}{l}\text { Urinary } \\
\text { excretion } \\
\text { hydroxyproline } \\
\text { (mg/day) }\end{array}$ \\
\hline 1 & 3220 & 6 & 1.04 & 38.7 & 13 & 43.0 \\
\hline 2 & 3370 & 6 & 0.96 & 26.7 & 9 & 40.6 \\
\hline 3 & 3630 & 6 & 1.07 & 31.5 & 11 & 57.7 \\
\hline 4 & 3660 & 6 & 1.10 & 28.0 & 7 & 57.3 \\
\hline 5 & 3050 & 7 & 1.21 & 29.9 & 10 & 55.8 \\
\hline 6 & 3800 & 5 & 0.91 & 29.6 & 10 & 34.7 \\
\hline 7 & 3690 & 7 & 0.98 & 26.9 & 10 & 44.6 \\
\hline 8 & 3280 & 7 & 0.96 & 22.4 & 9 & 51.5 \\
\hline 9 & 3475 & 6 & 0.92 & 23.9 & 9 & 42.0 \\
\hline 10 & 3240 & 5 & 1.03 & 29.2 & 11 & 43.0 \\
\hline 11 & 2640 & 5 & 1.05 & 32.4 & 13 & 42.8 \\
\hline
\end{tabular}

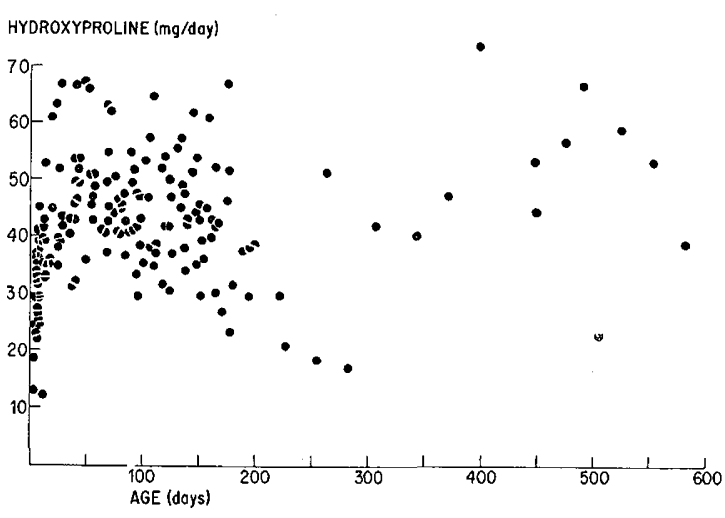

Fig.1. Rate of urinary excretion of hydroxyproline in relation to age of normal male infants. Each point refers to results of analysis of one 72-hour collection of urine.

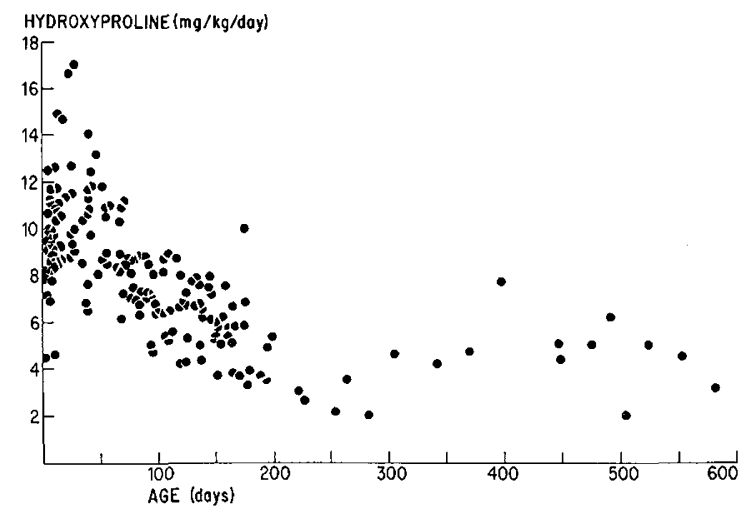

Fig. 2. Rate of urinary excretion of hydroxyproline per kilogram of body weight in relation to age of normal male infants. Each point refers to results of analysis of one 72-hour collection of urine. 


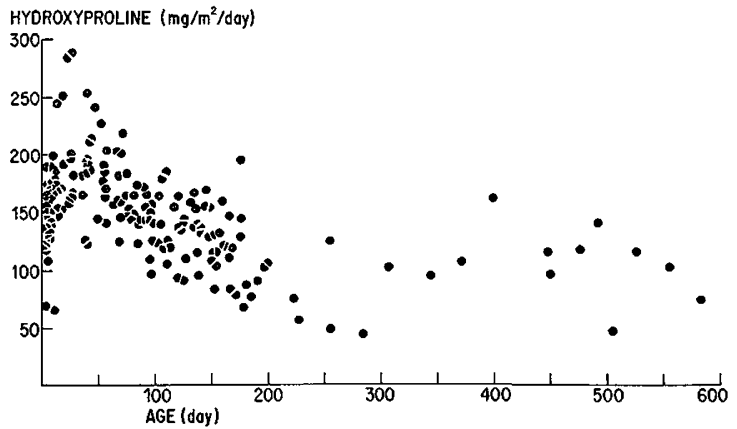

Fig. 3. Rate of urinary excretion of hydroxyproline per unit of body surface area in relation to age of normal male infants. Each point refers to results of analysis of one 72-hour collection of urine.

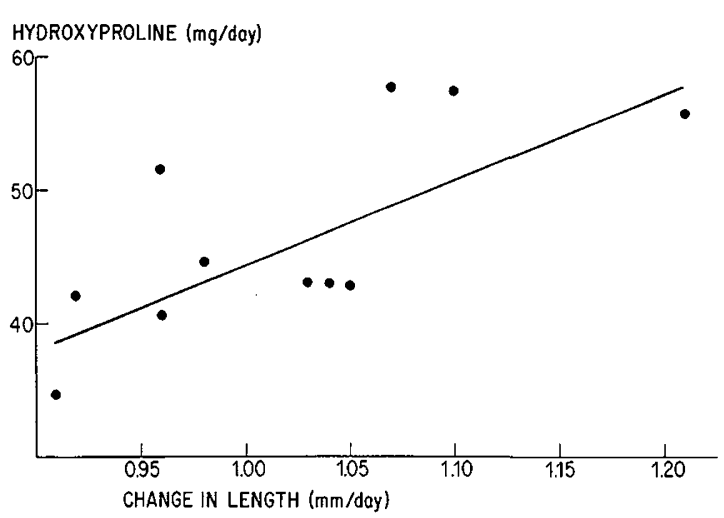

Fig.4. Mean rate of urinary excretion of hydroxyproline in relation to rate of change in length by male infants between 20 and 120 days of age. Each point summarizes results of studies with one infant. The calculated regression is also shown.

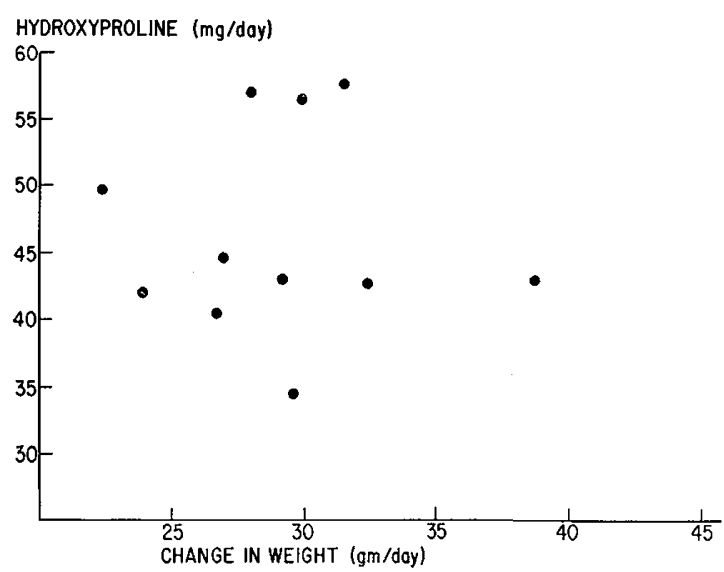

Fig. 5. Mean rate of urinary excretion of hydroxyproline in relation to rate of change in weight by male infants between 20 and 120 days of age. Each point summarizes results of studies with one infant.

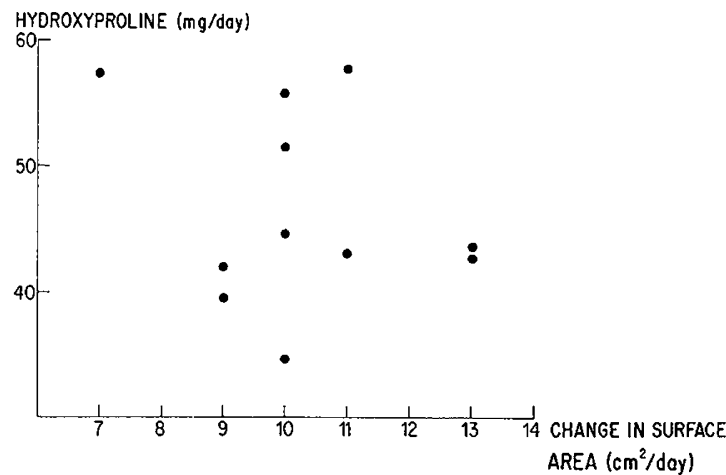

Fig. 6. Mean rate of urinary excretion of hydroxyproline in relation to rate of change in surface area by male infants between 20 and 120 days of age. Each point summarizes results of studies with one infant.

\section{Comment}

Urinary excretion of endogenous hydroxyproline reflects rate of degradation of collagen, which, in turn, is related at least in part to rate of synthesis of collagen. Disorders in which rates of urinary excretion of hydroxyproline are depressed include malnutrition, hypothyroidism and dwarfism, whether of pituitary or other nature, and infantile protein-calorie malnutrition $[6,7,11,13,17,18]$. Disorders associated with increased rates of urinary excretion of hydroxyproline include hyperthyroidism, malabsorption syndromes, rickets and vitamin D-resistant rickets. Rates of excretion are also increased during recovery from infantile protein-calorie malnutrition.

Because the determination of the rate of excretion of hydroxyproline may have clinical usefulness, establishment of the range of normal values at various ages is desirable. Previously published data on excretion of hydroxyproline by normal infants are not extensive. KLEIN and TEREE [10] have reported results of analysis of 38 specimens of urine from normal infants ranging from 1 to 60 days of age. Each urine specimen represented a 12- or 24-hour collection. Rates of excretion ( $\mathrm{mg} /$ day) increased rapidly during the first two weeks of life and then more gradually. The increasing rates of excretion are, of course, demonstrated more dramatically during the early days of life by study of $12-$ to 24-hour specimens of urine than by the 72-hour specimens examined in the present study.

The mean rate of urinary excretion of hydroxyproline ( $38.8 \mathrm{mg} /$ day) in 15 studies of infants between 9 and 20 days of age (table I) is somewhat less than the value $(45.4 \mathrm{mg} /$ day) reported by KLEIN and TereE [10] from study of 13 infants in this age range. The results of KLEIN and Teree may have been falsely high because of inclusion of chromogenic substances other 
than hydroxyproline. Such materials are largely excluded by the distillation procedure of SERAFInI-CESSI and CEssi [16] used in the present study.

Alluson et al. [1] have reported considerably lower rates of urinary excretion of hydroxyproline by young infants than those reported by KLEIN and TEREE [10] and those described in this paper. However, Allison et al. state that the urine was frozen (presumably without acidification) before analysis, a practice that we have found to result in decrease in concentration of hydroxyproline.

Previously reported data concerning urinary excretion of hydroxyproline by infants older than two months are extremely meager. JASIN et al. [6] reported mean urinary excretion of hydroxyproline of $32.7 \mathrm{mg} /$ day (range 17.6 to 43.0 ) for seven normal infants between birth and 12 months of age. In relation to surface area, the mean excretion was $102.2 \mathrm{mg} / \mathrm{m}^{2} /$ day (range 48 to 130). Similar values were found for nine hospitalized infants. Krvirikko and LAITINEN [7] reported a mean excretion of $115.4 \mathrm{mg} / \mathrm{m}^{2} /$ day (standard deviation 40.3 ) for 24 infants between birth and 12 months of age.

Data presented here and in the report by KLEIN and TEREe [10] suggest that urinary excretion of hydroxyproline may be conveniently expressed as milligrams per day. After the first few days of life, the normal range will then be found to remain relatively constant throughout infancy. On the other hand, if values are expressed in relation to surface area, normal values will be found to differ remarkably with age. For example, mean rates of excretion in the present study were $191.1,123.7$ and $95.9 \mathrm{mg} / \mathrm{m}^{2} /$ day, respectively, for the age intervals 21 to 60,121 to 200 and 201 to 582 days of age (table I).

Other investigators $[2,8,9]$ have concluded that urinary excretion of hydroxyproline reflects rate of metabolism of collagen in bone. The correlation demonstrated in the present study between rate of gain in length and average rate of urinary excretion of hydroxyproline supports this conclusion.

\section{References and Notes}

1. Allison, D.J.; Walker, A. and Smith, QT.: Urinary hydroxyproline: creatinine ratio of normal humans at various ages. Glin. chim.Acta 14 : 729 (1966).

2. Dull, T.A. and Henneman, P.H.: Urinary hydroxyproline as an index of collagen turnover in bone. New Engl.J. Med. 268: 132 (1963).

3. Fomon, S.J.; Thomas, L.N.; Jensen, R.L. and MAY, C.D.: Determination of nitrogen balance of infants less than 6 months of age. Pediatrics 22: 94 (1958).

4. Fomon, S.J.; Younoszal, M.K. and Thomas,
L. N.: Influence of vitamin D on linear growth of normal full-term infants. J. Nutr. 88: 345 (1966).

5. Fomon, S.J.: Infant nutrition (Saunders, Philadelphia, Pa. 1967).

6. Jasin, H. E. ; Fink, C.W.; Wise, W. and ZIFF, M.: Relationship between urinary hydroxyproline and growth. J.clin. Invest. 41: 1928 (1962).

7. Krvirikko, K. I. and Laitinin, O.: Clinical significance of urinary hydroxyproline determinations in children. Ann. paediat.fenn. 11: 148 (1965).

8. Klein, L.; Albertsen, K. and Curtiss, P.H., Jr.: Urinary hydroxyproline in hyperparathyroidism: A study of three cases with and without bone lesions. Metabolism 11: 1023 (1962).

9. KLein, L. and Curtiss, P.H., Jr.: Urinary hydroxyproline as an index of bone metabolism; in Dynamic studies of metabolic bone disease (ed. Pearson, O.H. and Joplin, G.F.), p.201 (Blackwell Scientific Publications, Oxford 1964).

10. Kuern, L. and Teree, T. M. : Skeletal metabolism in early infancy: Urinary hydroxyproline. J. Pediatrics 69: 266 (1966).

11. Laitinen, O.; Nikkmla, E.A. and Kivirikko, K. I.: Hydroxyproline in the serum and urine. Normal values and clinical significance. Acta med.scand. 179: 275 (1966).

12. Neuman, R.E. and Logan, M.A.: The determination of hydroxyproline. J. biol. Chem. 184: 299(1950).

13. Prcou, D.; Alleyne, G.A.O. and Seakins, A.: Hydroxyproline and creatinine excretion in infantile protein malnutrition. Clin. Sci. 29: 517 (1965).

14. Prockop, D.J. and Udenfriend, S.: A specific method for the analysis of hydroxyproline in tissues and urine. An. Biochem. 1: 228 (1960).

15. Prockop, D.J.: Isotopic studies on collagen degradation and the urine excretion of hydroxyproline. J. clin. Invest. 43: 453 (1964).

16. Serafini-Cessi, F. and Cessi, G.: An improved method for determination of hydroxyproline in protein hydrolyzates. An. Biochem. 8:527 (1964).

17. Sjoerdsma, A.; Udenfriend, S.; Keiser, H. and LERoy, E. C. : Hydroxyproline and collagen metabolism. Clinical implications. Combined clinical staff conference at the National Institutes of Health. Ann.intern. Med. 63: 672 (1965).

18. SmILEy, J. D. and ZIFF, M.: Urinary hydroxyproline excretion and growth. Physiol. Rev. 44: 30 (1964).

19. WhiteheAd, R. G.: Hydroxyproline creatinine ratio as an index of nutritional status and rate of growth. Lancet $i i$ : 567 (1965).

20. Supported in part by USPHS grants HD-00383, $5 \mathrm{~K} 3 \mathrm{HD}-2465$, and $5 \mathrm{TI}$ AM 5246.

21. Fomon, S.J., M.D., Professor, Department of Pediatrics, University of Iowa, Iowa City, Iowa 52240 (USA). 